\title{
Pigment Formation in L-forms of Serratia marcescens
}

\author{
By E. G. HUBERT, C. S. POTTER, \\ G. M. KALMANSON AND L. B. GUZE \\ Veterans Administration Center, Los Angeles, California (90073), \\ and UCLA School of Medicine, Los Angeles, California (90024), U.S.A.
}

(Accepted for publication Io September I968)

\begin{abstract}
SUMMARY
L-forms of Serratia marcescens were produced and serially transferred in osmotically stabilized agar with penicillin. The bacterial form was pigmented, while the L-form colony was not. Lack of colour in the L-form colony was not due to pigment diffusion into the agar; an extract of agar with L-form growth did not show an absorption spectrum for prodigiosin.
\end{abstract}

\section{INTRODUCTION}

Although considerable information has accumulated about the chemical steps in the synthesis of the red pigment 'prodigiosin' by Serratia marcescens, little is known of the site of synthesis. Purkayastha \& Williams (1960) found that acetylhexosamine and pigment content of various fractions of the organism paralleled each other and concluded that this was evidence that the pigment was contained in the cell 'envelope'. From their results, the authors were unable to determine whether the pigment was located in the plasma membrane or wall portion of the cell envelope. However, since lysozyme treatment resulted in the release of a clear supernatant fluid containing hexosamine, they suggested that the 'pigment might be located in the cell or plasma membrane'. L-forms are microbial forms with part or all of their cell wall missing and would, therefore, be a suitable tool for determining the importance of cell wall in pigment production and/or localization. The present studies were designed to prepare $\mathbf{L}$-forms of $S$. marcescens in order to determine whether they could produce pigment.

\section{METHODS}

Bacteria. A pigmented strain of Serratia marcescens, originally obtained from a throat culture of a patient, was used throughout.

Media. Several different osmotically stabilized media were tried for L-form production and propagation. The best was brain heart infusion agar (Difco) $+\mathrm{I} \cdot 8 \%$ sodium chloride $+0.00 \mathrm{I} \% \mathrm{MgSO}_{4} \cdot 7 \mathrm{H}_{2} \mathrm{O}$, inactivated (56 for $30 \mathrm{~min}$.) $20 \%(\mathrm{v} / \mathrm{v}$ ) agamma horse serum (Hyland), and $10 \%(\mathrm{w} / \mathrm{v})$ yeast extract (Robbins and Fleischmann were both satisfactory). The bacterial form was routinely maintained on brain heart infusion agar. The bacterial form was grown on the medium used for growing the L-form for experiments involving pigment production.

Production of L-forms. Bacteria were inoculated as either a pour or streak plate on media containing various amounts of penicillin and incubated aerobically. The plates were examined daily; when L-forms were noted after several days, serial transfers 
were made as follows: approximately one-quarter of the agar plate with L-form growth was mashed in $9 \mathrm{ml}$. liquid medium with the same composition as the agar in a Tri-R Homogenizer (Tri-R Co.), and I and $0 . \mathrm{I} \mathrm{ml}$. samples used to inoculate fresh medium for pour and streak plates. Because L-forms grew better in pour plates, routine serial transfer was done with pour plates. The streak plates were used to examine colony morphology with low power microscopy.

Although 500 units penicillin $/ \mathrm{ml}$. was sufficient for initial production of L-forms, the penicillin concentration had to be increased to $30,000 \mathrm{units} / \mathrm{ml}$. to prevent reversion to bacterial form during subsequent propagation. All incubations were aerobic and, as a compromise between conditions for pigmentation and for L-form growth, at $30^{\circ}$. The L-forms have now been serially transferred a total of $6 \mathrm{r}$ times at approximately twice-weekly intervals, without any visual evidence of reversion.

Extract of pigment. A modification of the method of Hubbard \& Rimington (1950) was used. To obtain a large quantity of L-form growth of characteristic morphology, these forms were grown on the surface of nutrient agar in Kolle flasks. The bacterial form was grown in plastic Petri dishes (Falcon). For extraction of pigment, the nutrient agar with bacteria was homogenized with I ml. liquid medium for each $2 \mathrm{ml}$. nutrient agar in a Tri-R Homogenizer. Because of the large volumes involved, the L-form growth and agar were homogenized in a Waring blender with liquid medium in the same proportion. The volume of homogenate was measured and Io g. solid $\mathrm{NaOH}$ dissolved in each $100 \mathrm{ml}$. of homogenate. The mixture was allowed to stand for $2 \mathrm{hr}$. An equal volume of absolute ethanol was mixed with the homogenate, followed by an equal volume of light petroleum. The mixture was shaken and separated in a separatory funnel. The petroleum phase was saved, and the aqueous phase re-extracted twice more with the same volumes of light petroleum. The combined petroleum fractions were reduced in volume over low heat and allowed to dry at room temperature $\left(20^{\circ}\right)$. The residue was dissolved in $3 \mathrm{ml}$. absolute ethanol and $0.03 \mathrm{ml}$. concentrated hydrochloric acid added to ensure that the prodigiosin was in acidic form. Suitable dilutions of the bacterial extract were made in absolute ethanol (no dilution was necessary for the L-form extract). The spectrum of both extracts was taken on a Beckman DU spectrophotometer.

\section{RESULTS}

It was noted from the beginning that L-form colonies appeared to be colourless. Although visual evidence suggested that the L-forms were not producing pigment, the possibility existed that they were, but that because of lack of an intact cell wall, the pigment was diffusing into the agar and thus was not noticed. Accordingly, extraction of nutrient agar in which L-forms were growing was done to determine whether pigment was present. To obtain approximately equal numbers of $\mathrm{L}$-forms and bacteria, eight Kolle flasks were heavily streaked with L-form mash, a Petri dish streaked with the bacterial form, and all were incubated for 8 days. The results of the extraction procedure are shown in Table $\mathrm{I}$. The absorption spectrum of $\mathrm{L}$-form extract did not at all resemble that of the bacterial form extract, having no peak at $540 \mathrm{~m} \mu$ as had the bacterial form extract. Thus, it was unlikely that L-form mash contained any prodigiosin. However, even if the very small absorption at $540 \mathrm{~m} \mu$ (no peak) did represent prodigiosin, it could not have been more than $1 \%$ of that produced by a comparable number of bacterial forms. The question arose whether the amount of 
potassium and citrate in buffered penicillin could in some way inhibit pigment production. Accordingly, $60 \mathrm{~m}$-equiv. $\mathrm{K}^{+} / 1$. and $3.4 \mathrm{~m}$-mole trisodium citrate/1. (amounts present in 30,000 units penicillin $/ \mathrm{ml}$.) were added to the salt +horse serum + yeast agar. When the bacterial form of Serratia marcescens was streaked on the surface, the colonies grew uniformly pigmented.

Table I. Determination of the amount of prodigiosin produced by bacterial and L-forms of Serratia marcescens

$\begin{array}{lcc} & \text { L-forms } & \text { Bacteria } \\ \text { Total number of colony-forming units extracted } & 2 \cdot 88 \times 10^{10} & 2 \cdot 98 \times \text { IO }^{10} \\ \text { Volume of ethanol in which extract was dissolved for } & 3.03 & 75.8 \\ \mathrm{~A}_{540} \text { reading } & 0.193 & 0.850 \\ \mathrm{~A}_{540} \text { obtained } & 5.32 & 585\end{array}$

* Using Hubbard \& Rimington's (1950) value of the molar extinction coefficient of the acidic form of prodigiosin $\mathrm{I} 10,000$ at $540 \mathrm{~m} \mu$.

\section{DISCUSSION}

The location of the metabolic block in L-forms of Serratia marcescens leading to lack of pigment production is not known. The sequence of chemical events leading to pigment production has recently been summarized by Morrison (I966). The current schema for late steps in prodigiosin production is that there is synthesized a volatile monopyrrole precursor, 2-methyl-3-n-amyl-pyrrole (MAP). In a separate sequence, a bipyrrole precursor, 4-methoxy-2,2'-bipyrrole-5-carboxaldehyde (MBC), is synthesized. The final step is the coupling of the mono- and bipyrrole precursors.

The failure of L-forms to produce pigment may be that: (I) L-forms were originally selected by penicillin from non-pigment forming mutants. This is probably negated by the fact that, when penicillin is removed, reversion is to uniformly pigmented forms. (2) A metabolic block may prevent synthesis of the mono- or dipyrrole precursors. (3) The coupling enzyme is not synthesized or cannot act. (4) The cell wall is necessary as a physical site for one or more of the above (Monk, 1957). It is only the latter postulate that is in accord with the known action of penicillin, i.e. inhibition of cell wall synthesis. Otherwise, another action of penicillin would need to be postulated.

\section{REFERENCES}

Hubbard, R. \& Rimington, C. (1950). The biosynthesis of prodigiosin, the tripyrrylmethene pigment from Bacillus prodigiosus (Serratia marcescens). Biochem. J. 46, 220.

Monk, G. W. (1957). Spectral absorption of prodigiosin in intact cells. J. Bact. 74, 7I.

Morrison, D. A. (1966). Prodigiosin synthesis in mutants of Serratia marcescens. J. Bact. 91, I 599.

Purkayastha, M. \& Williams, R. P. (1960). Association of pigment with the cell envelope of Serratia marcescens (Chromobacterium prodigiosum). Nature, Lond. 187, 349. 